\title{
AN ELECTRIC CIRCUITS' REMOTE SWITCHING SYSTEM BASED ON GSM RADIO NETWORK
}

\author{
Gerard Rushingabigwi ${ }^{1}$, Liguo Sun $^{2}$, Godfrey Lugoloobi ${ }^{3}$, Frank Mwezi ${ }^{4}$ \\ ${ }^{1}$ Department of Electronic Engineering and Information Science, University of Science and Technology of China \\ (USTC), P.R China 96 JinZhai Road Baohe District, Hefei, Anhui, 230026, P.R.China \\ ${ }^{2}$ Department of Electronic Engineering and Information Science, University of Science and Technology of China \\ (USTC), P.R China 96 JinZhai Road Baohe District, Hefei, Anhui, 230026, P.R.China \\ ${ }^{3}$ Department of Electrical and Electronics Engineering, University of Rwanda, College of Science and Technology \\ (UR-CST), Republic of Rwanda Avenue de l'Armée, PoBox 3900 Kigali, Rwanda \\ ${ }^{4}$ Department of Electrical and Electronics Engineering, University of Rwanda, College of Science and Technology \\ (UR-CST), Republic of Rwanda Avenue de l'Armée, PoBox 3900 Kigali, Rwanda
}

\begin{abstract}
Mobile phone industry is classified among the fastest growing engineering branches. It has to be exploited for vast applications, reliability and affordability. Mobile cellular phone subscribers have reached saturation point; with such information, the basic cell phone that was mainly utilized to make calls will also be utilized for remote switching and control activities. The now developed system is based on the global system for mobile communications (GSM) radio network: it will operate as a very long distance remote switch. Utilizing the daily cell phone, a user will either put on/off any desired electric circuit located in an owned, controlled compound. Two cell phones are provided, one being a mobile transmitter user end and another being referred to as a fixed receiver end. A signal will be sent from the user end to put a consumer's electric circuit either on or off at the receiver end; afterwards, the receiver end will notify the user-end about the on/off state of the consumer. The particularity of this publication is the system simplicity, yet cheap and safe, so that even very low income cell phone users can enjoy radio frequency (RF) technology's increasing applications. The software utilized to develop and simulate circuits is the linear technology, LT spice. The calculative theory has quantitatively enriched the methodology. Both the building blocks and the physical implementation diagrams for the system are herein contained. The remote switching system based on GSM radio network has been successfully designed, implemented, tested and its functionality has been examined.
\end{abstract}

Keywords: Radio communication, LTspice, GSM, ON/OFF control

\section{INTRODUCTION}

The authors' motivation is to design and construct a circuit switching mechanism backed by the widely available GSM network. The system will remotely switch any electric circuit from a very far location using any cell phone, provided that it is compatible with GSM network; the system differs from the existing ones in both architecture and operating modes.

The mechanism is implemented utilizing a mobile phone operated switch with on/off status notifications to the end user. It brings solutions to the short range wireless technology, the under-exploited communication links and the employments of unskilled house helpers. Section two discusses a couple of works that were recently carried out in similar domain: the cell phone based remote control and switching systems. Section two presents the step by step design of the sub-circuits of the system in question. Under this section, computation theory is encountered; the section is ended by results and discussions. Section three is for conclusion while the last section, section four is reserved for references.

\subsection{Related Existing Applications}

The applications of GSM cellular telephony are so numerous that the authors invite the reader of this article to quickly overview the past and future of GSM radio network, a backbone to the present work. Important to know is that most services in most developping countries are now based on second generation (2G), dominated by GSM [1]. The cell phone network can be utilized in wireless security system and switching applications [2,3], telemedicine [4], remote control [5,6], and so on and so forth.

The home owners in [5] will seem to travel with their home in hands provided the home is Internet connected.

For the Android operating system based robot system in [6], the remote control is done by an embedded processor correlated with Android operating system and the robot, all controlled on a smart phone by the remote user.

In [7], the java enabled Android smart phone under GSM cellular communication network serves as a remote control tool by interacting with a system made by 8051 microcontroller and GSM Modem, which will be sending 
short messages to user's mobile cell phone in case of intrusion.

According to different sources $[1,8,9]$ however, generations of cellular phone systems are popularly known from first generation $(1 \mathrm{G})$ to fourth generation $(4 \mathrm{G})$ in 2011.

Regarding the fifth generation (5G), a couple of publications certify the possibilities in design and operation of the 5th generation cellular networks [8,9]. According to [10], a 5G heterogeneous wireless cellular architecture is proposed.

Surveying the past and future of cellular telephony $[8,9]$, looking at the state of the art of cellular industry's increasing applications, an additional system is now developed as a cost effective solution to remotely control the home electric consumers, in friendship with the owner. By a touching on a simple second generation's GSM cell phone button from anywhere around the world, a person will put on/off the electric circuit at his/her compound, provided that GSM network is covered.

\section{THE PROPOSED SYSTEM'S CIRCUIT

DESIGN, FUNCTIONALITY AND

\section{IMPLEMENTATION}

A circuit will accept a signal from a cell phone, and shall process the signal to switch the circuit either on or off. The system architecture's block diagram is presented in Fig. 1. Though the advanced cell phone can be utilized, the required cell phone doesn't need to be of any specific brand, it must be any cell phone compatible with GSM radio network, a model is shown in Fig. 2.

The work being achieved through a step by step flow in Fig. 3 , the realization is done in putting together the designed circuits in Fig. 4 up to Fig. 10 while Fig. 11 depicts the physically realized system's prototype.

The transmitter mobile phone will dial the receiver fixed phone's subscriber identity module (SIM) card number. Backlight display is utilized as a signal for this system, knowing that the ringing styles are normally defined as ring tone, vibration, backlight display and others by the user. Thus, the backlight signal is entered to the ring detector circuit, which plays a vital role for the system's core. The ring detector circuit produces an output signal which controls the clock circuit.

The clock is an essential timing instrument setting up a timing sequence within the circuit to control the on/off times of the circuit $[13,14]$.

The control is done through sequential generation of clock pulses each time the receiver phone rings. Analogous to a switch, the clock acts a master set or reset. The clock circuit output is then input to the decision circuit. The decision circuit will, at a particular sequence of the clock pulse, switch the power to control the load and notification circuits. The decision circuit chooses which circuit to be powered at any given sequence of the clock pulse. The output from the decision circuit is fed into the power control circuit; which performs the actual switching between the load on and off notification circuits.

The compound's security is ensured by configuring the receiver phone number in way that only calls from intended users are accepted.

\subsection{The System's Circuit Design and Functionality}

The ordinary GSM phone will be permanently attached with a switching circuit, which will be referred to as the receiver unit. This phone will remain functional all the times. For security of the entire system, the receiver unity's SIM card number must be configured to receive only a few other numbers. When the receiver cell phone is called through these assigned numbers, the receiver phone's ring tone becomes active to control the circuit.

The system is an economy oriented switching concept and ensures the switching safety and maintenance since there will be no sparks generated. Operated appliances will be switched either on/off at the appropriate time and from a very long distance; thus improving on the manually operated switches. For instance, a Universities may use this project prototype to reduce the cost of administering its electronic equipments, which economizes manpower who used to literary operate and control the switching of lights, projectors and other electrical/electronic appliances.

In short, the transmitting cell phone will communicate with another cell phone, referred to as receiver-end. The transmitter and receiver intermediated with the analogue electronic circuit, will serve to remotely switch for any electric circuit.

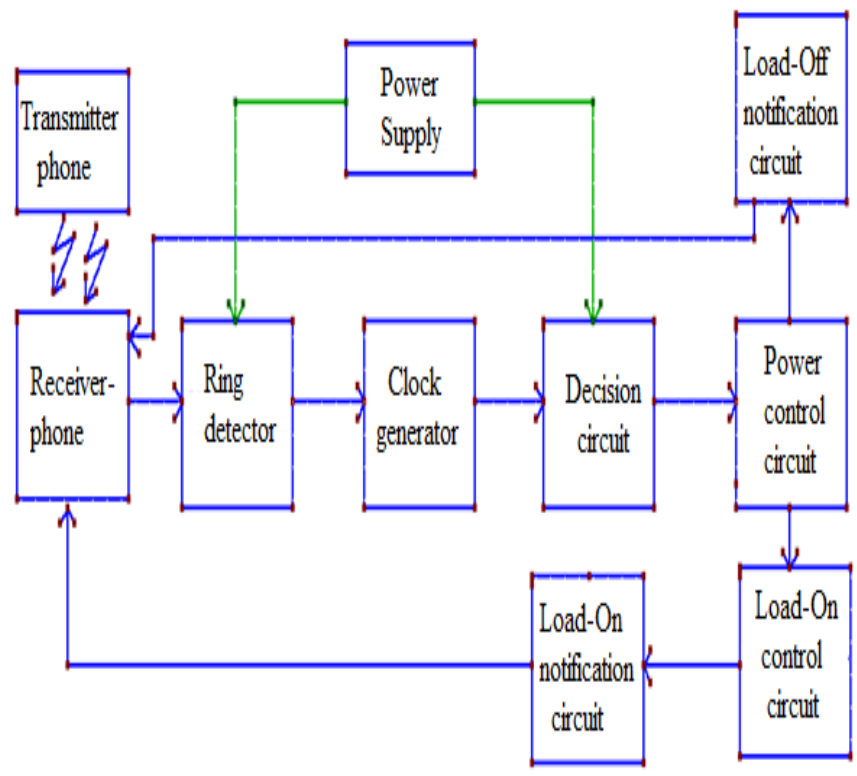

Fig- 2: The system architecture 


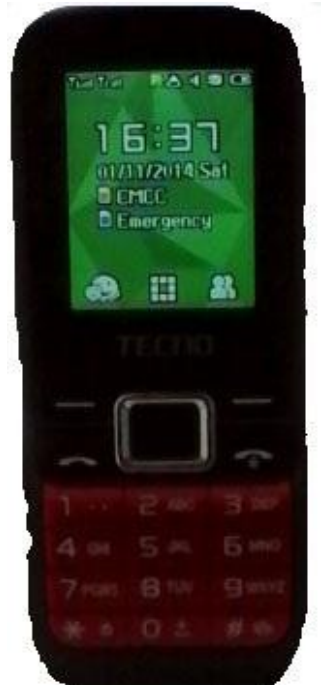

Fig- 2: Utilized cell phones' model

\begin{tabular}{|c|c|c|}
\hline \multirow{2}{*}{ 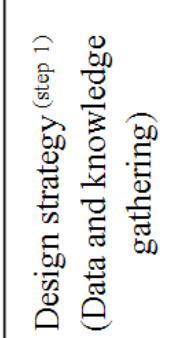 } & $\begin{array}{l}\text { Circuit development stage } \text { (step 2) }^{\text {2) }} \\
\text { (Block diagrams, LTspice } \\
\text { software and implementation) }\end{array}$ & \multirow{2}{*}{ 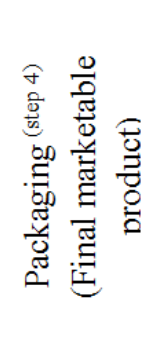 } \\
\hline & $\begin{array}{l}\text { Test phase }{ }^{\text {(step } 3)} \\
\text { (Practical results) }\end{array}$ & \\
\hline
\end{tabular}

Fig- 3: Step by step flow of the design activities
The research and practices were conducted in the University's electrical and electronics laboratory as well as workshops. The circuits have been constructed and the system functionality was properly tested.

The $\pm 12 \mathrm{~V}$ and $5 \mathrm{~V}$ power supplies are required for proper operation of the circuitry. Due to the use of integrated regulators, the transformer must supply at least $2 \mathrm{~V}$ greater than the required regulated output. Therefore, a $15 \mathrm{~V}-0-15 \mathrm{~V}$, 1 Ampere center tapped transformer, was chosen [15]. The design details are given in Fig. 4 where twelve volts, three terminal pin regulators are used because of their internal short-circuit current limiting, thermal overload protection and output safe-area compensation.

In Fig. 5, the 5V power supply circuitry was designed to ensure proper operation of the clock signal generator (74LS109). According to [16], the maximum supply voltage to the $74 \mathrm{LS} 109$ should be $5.5 \mathrm{~V}$.

The desired output voltage $\left(\mathrm{V}_{\text {out }}\right)$ of 5 volts, as per calculations [17] by equation (1),

$$
\mathrm{V}_{\text {out }}=\mathrm{V}_{\text {ref }}\left(\frac{\mathrm{R} 2}{\mathrm{R} 1+\mathrm{R} 2}\right)
$$

given the reference voltage, $\mathrm{V}_{\text {ref }}=1.25, \mathrm{R}_{1}=120 \Omega$; with the desired output voltage of 5 volts, the resistor $R_{2}$ is computed to be $120 \Omega$. Thus, with a variable resistor of $5 \mathrm{~K} \Omega$ in Fig. 5 , the 5-volts output will be obtained.

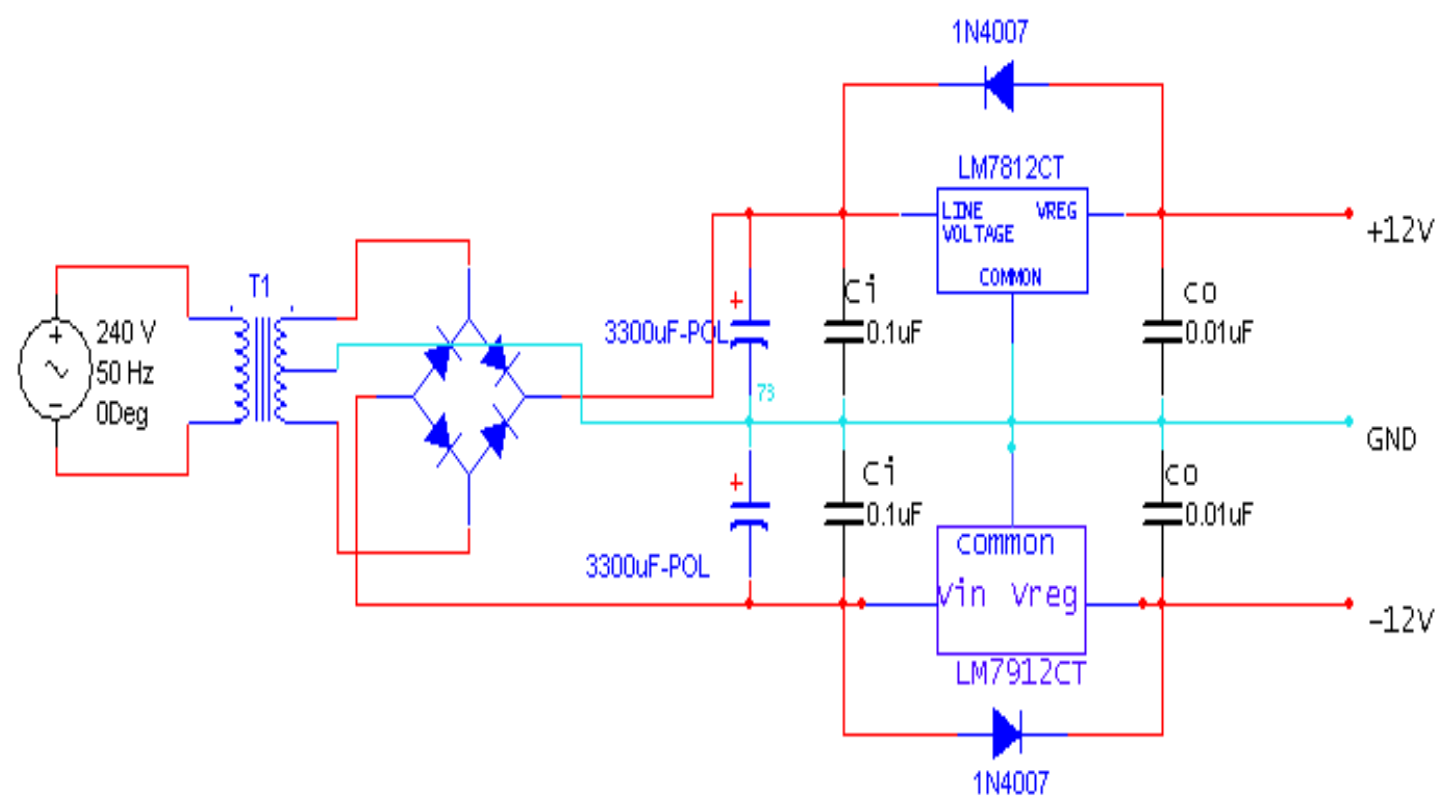

Fig-4: Design of a twelve-volt power supply circuitry. 


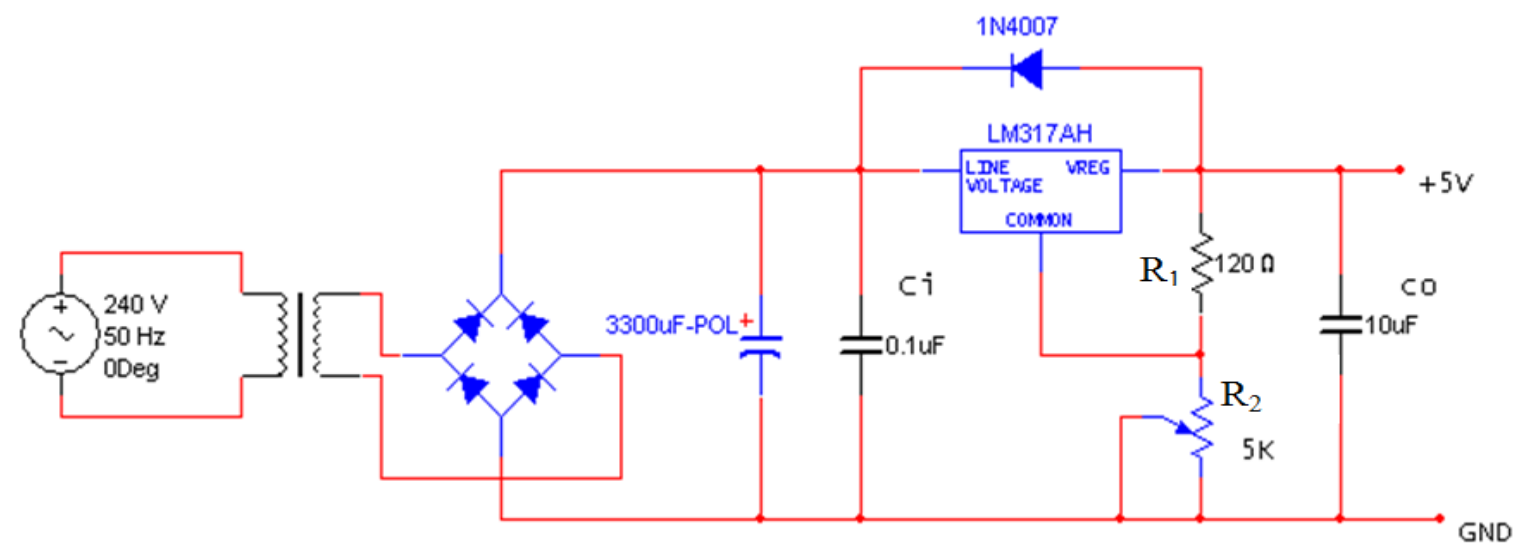

Fig-5: Design of a five-volts power supply circuitry

The ring detector circuit is used to detector the ringing of the receiver phone, indicating that the user wishes to:

a) switch on/off a particular load;

b) get a state of the load connected.

The ring detector circuit, at the center of the system in question, is thus designed in Fig.6.

Particularly to the present system, the ring detector circuit utilizes the use of light emitting diode (LED) back light displays as an input signal to signal an incoming call.

The decision circuit in Fig. 8, performs a pivotal role of switching between the on and off control circuits sequentially with respect to the ring signal. In other words the decision circuit performs the task of switching the load to an on or off status depending on what the previous status of the load was. The utilized clock circuit is arranged from a 555 timer monostable circuit $[14,18]$ which is triggered by the control signal from the ring detector circuit. The designed clock circuitry is shown in Fig. 6.

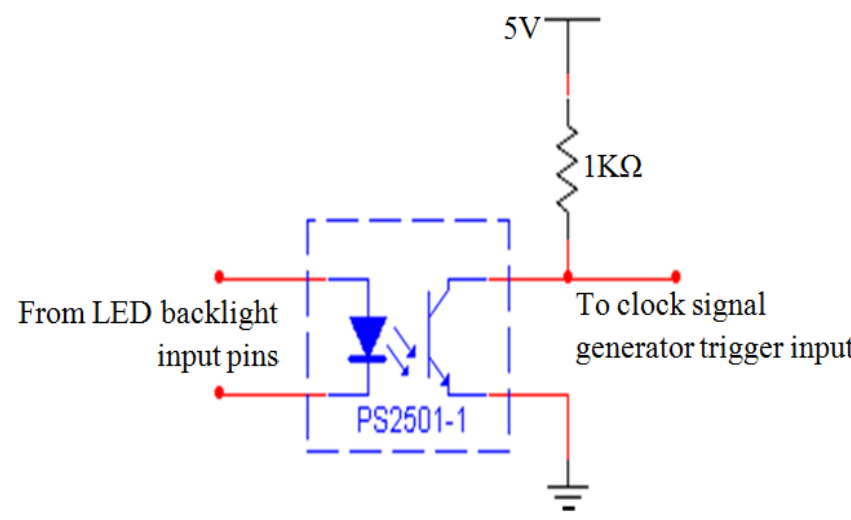

Fig-6: Design of the ring detector circuitry

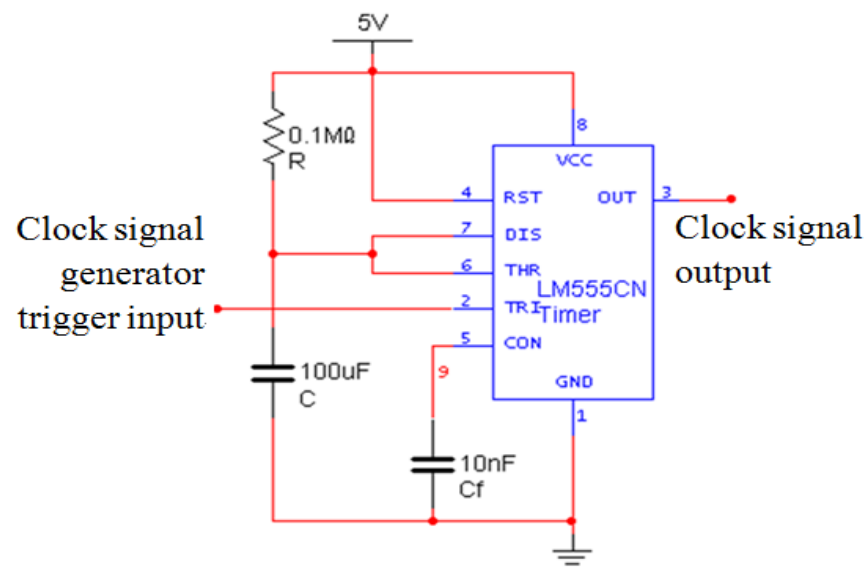

Fig-7: Design of the clock circuitry

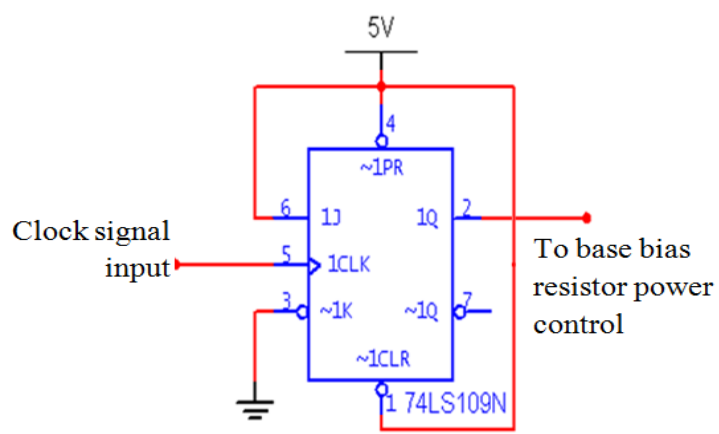

Fig-8: Design of the decision circuitry

The decision circuit is based on 74LS109A dual J and not K, positive edge triggered flip with preset and clear [16].

As the design work goes to the power control circuit shown in Fig. 9, the Q output from the decision circuit is applied to control the load-on and load-off power circuit relay. When the $\mathrm{Q}$ output is low the load off control and notification circuit is powered up and inversely when the $\mathrm{Q}$ output is high the load on and notification circuit is powered up.

In the power control circuit, a transistor switch is operating a double pole double throw $12 \mathrm{~V}$ relay. The relay acts to feed power to both the load-on and load-off control circuits. The utilized transistor is 2SC1815 type audio frequency general purpose amplifier [19]. The circuits are sequentially active, 
that's to say when the load-on circuitry is powered up then the load-off control circuit must be powered off; the converse being true. This is a role carried out by the power control circuit in Fig. 9.

In Fig. 10 and Fig. 11 respectively, both the load-on control and its notification circuit are designed. Put together, the circuit operates to switch the load relay on after $4 \mathrm{~s}$ and to keep it on till the next ring signal. At the center of the timing is a 741-Op-Amp [20, 21, 22] and a time delay network. When the load control circuit is activated, at the instant the load is switched on, the notification circuit is immediately activated. The circuit functions to momentarily connect the busy signal button; in that moment, the pending call would be canceled and the user receives a busy signal alert that the call has been ended by the receiver.

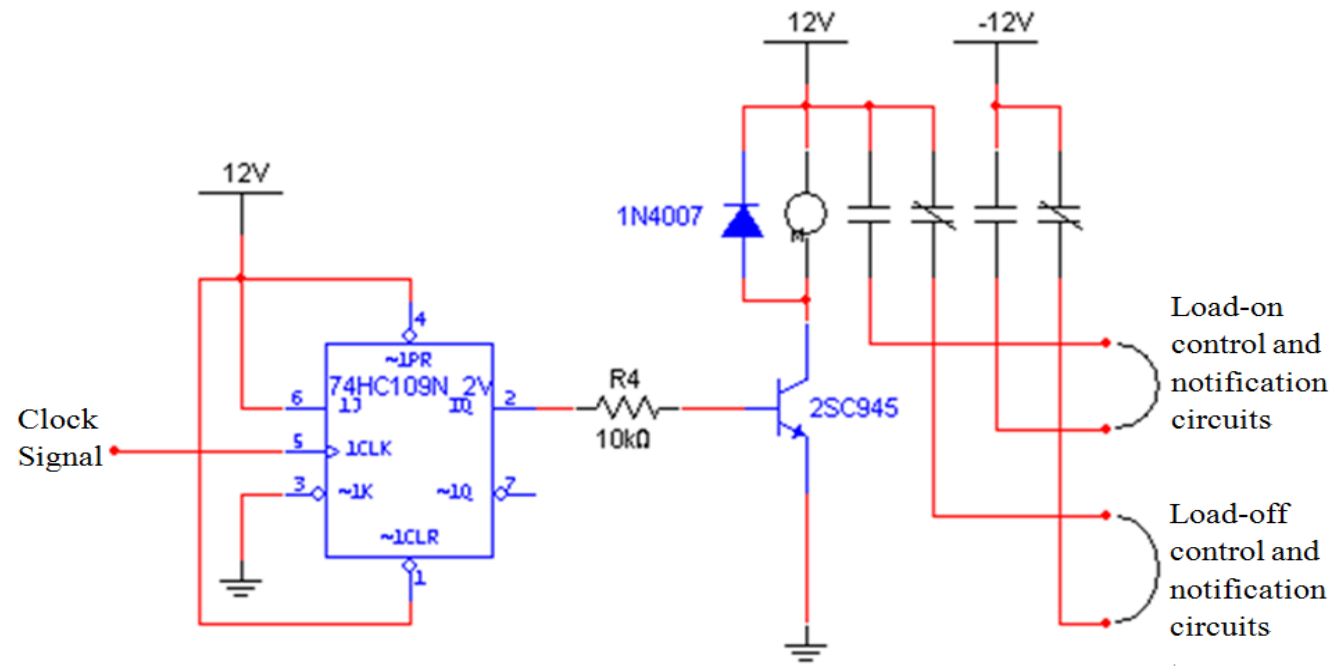

Fig-9: Design of the power control circuitry.

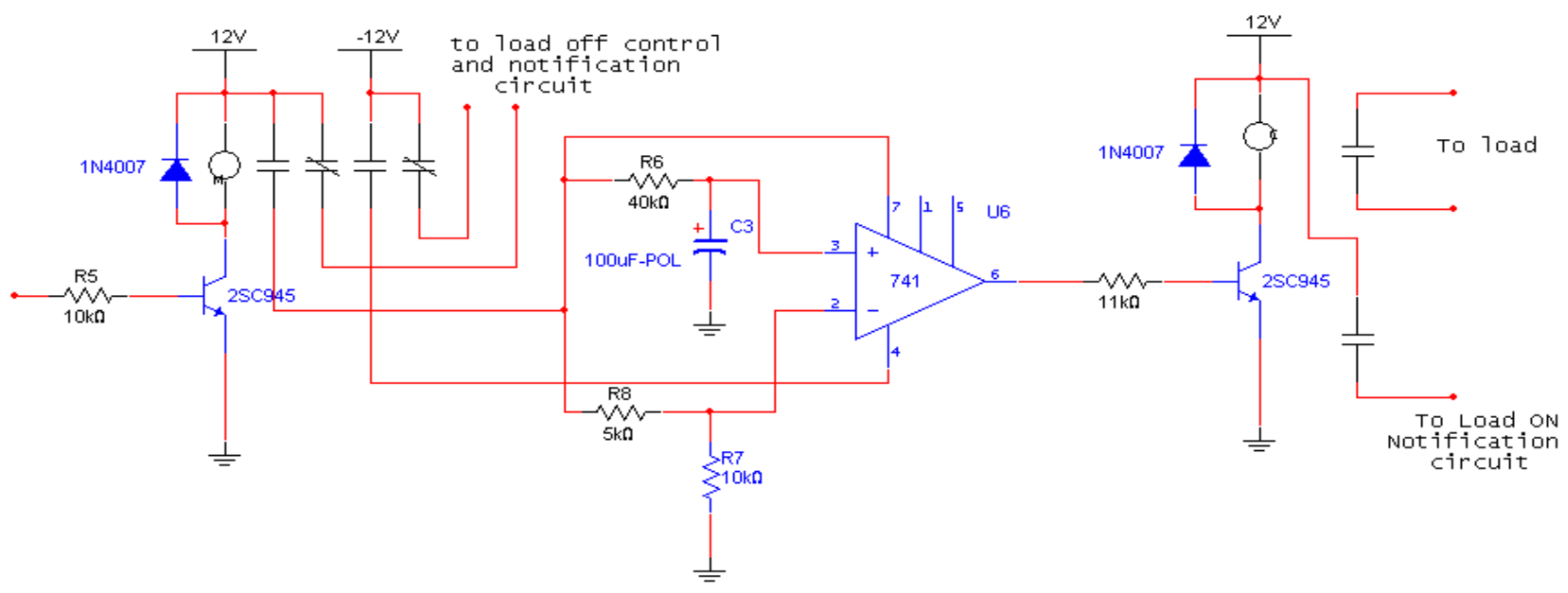

Fig-10: Design of the load on-control circuit

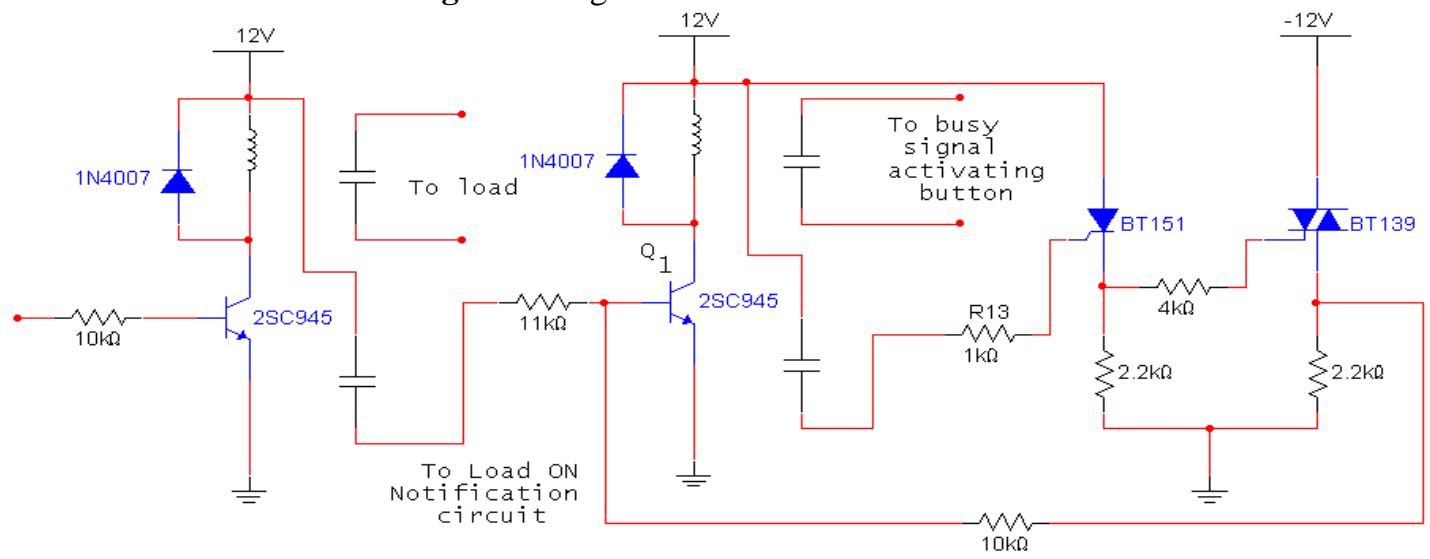

Fig-11: Design of the load-on notification circuitry 


\subsection{Computational Theory}

From the SCR datasheet [22,23], the peak anode current should not exceed 7.5A.

Considering the anode,

$$
12 V=I_{A} R_{L}
$$

With $\mathrm{R}_{\mathrm{L}}=2.2 \mathrm{k}$, the calculations give that $\mathrm{I}_{\mathrm{A}}=0.0054 \mathrm{~mA}$ which means that $2.2 \mathrm{~K} \Omega$ resistor is suitable as a load resistance for the anode is capable of holding such a small current.

From the datasheet it's defined for a $12 \mathrm{v}$ supply the maximum gate trigger current should not exceed $15 \mathrm{~mA}$.
With $\mathrm{R}_{\mathrm{g}}=1 \mathrm{~K}$ and applying equation (2), calculations give that $I_{g}=12 \mathrm{~mA}$.

Therefore the current is sufficient to keep the SCR on.

In Fig. 12, the design idea of the load-off notification circuit is based on a delay instant. When the receiver mobile starts ringing, after a delay of 6.8 seconds the user receives a busy signal notification indicating that the load is switched off, thus the call is terminated. Once transistor $\mathrm{Q}_{2}$ is on, the normally open contacts are engaged and the busy signal button of the receiver is activated. A busy signal alert is then sent to the receiver acknowledging that the load has been switched off.
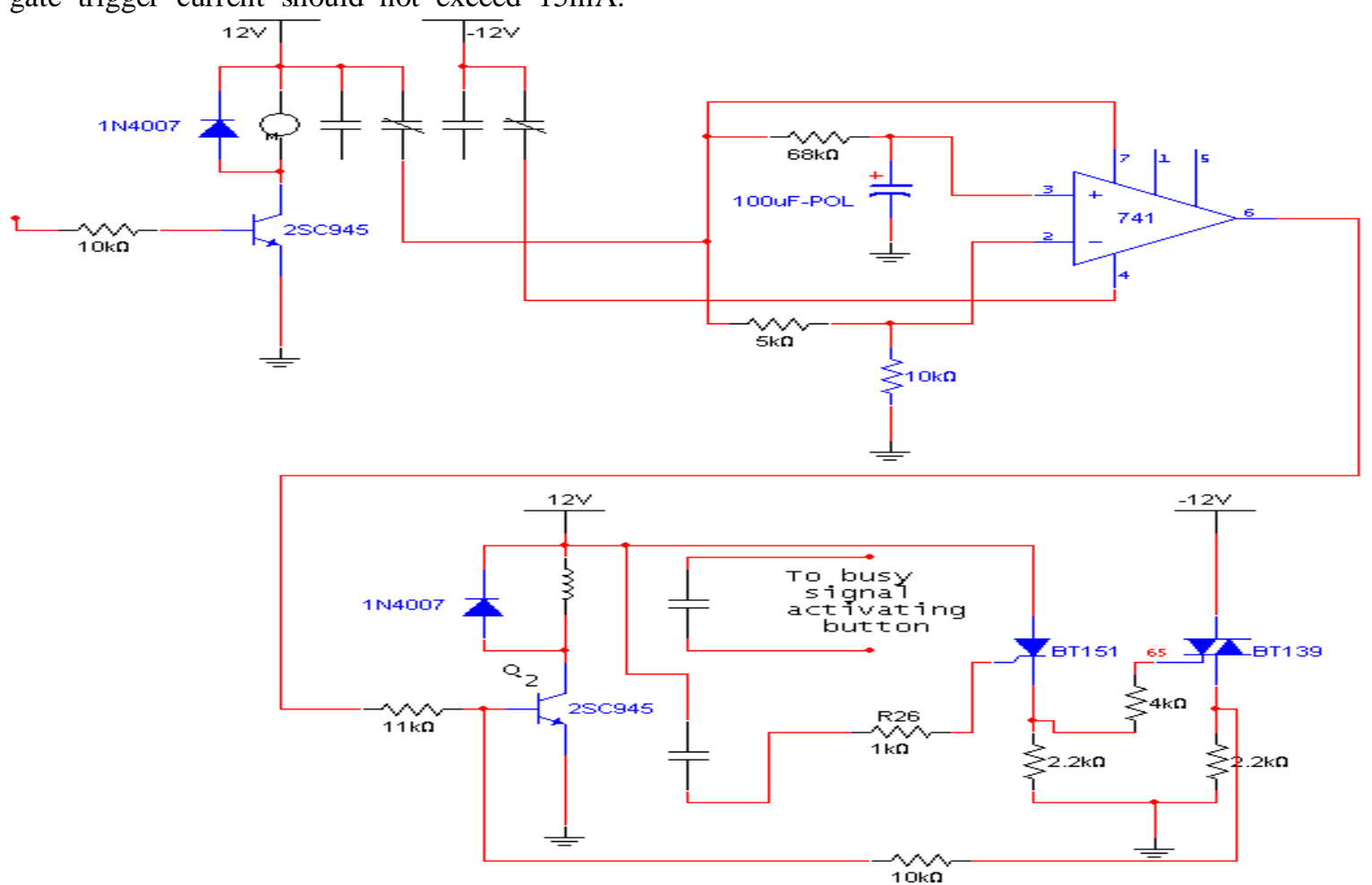

Fig-12: Load-off control circuit together with notification circuit

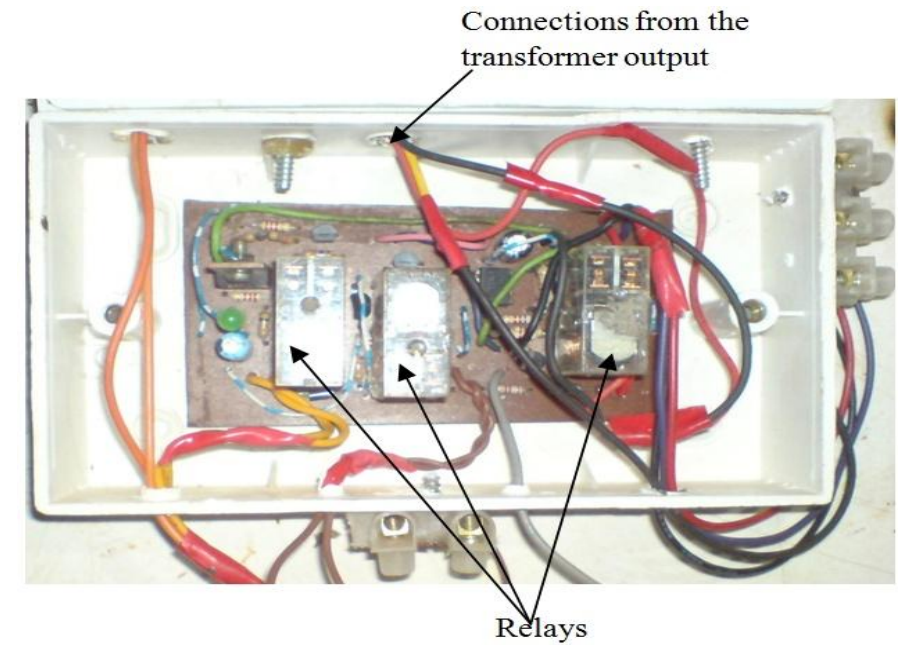

Fig-13: The picture of a tested prototype

\subsection{Results and Discussions}

The work has been implemented in practical circuit build ups. The system functionality has been tested and met the desired requirements. Interferences however have been experienced, notably when the user phone and the receiver phone are closer. The signal from the optical coupler is used to switch on the clock timer which in return, controls both the switching on and off states of the load.

Nonetheless, a good product cannot be marketed without being in a good package. The system implementation's picture is presented in Fig. 13, of which the packaging can be done in a competitive manufacturing telecommunication industry, utilizing molded boxes. 


\section{CONCLUSION}

Mobile phones are indispensable tools in people's daily life. Thus, the conceived cell phone based remote control system, all in the friendship with environment, can hit the target of improving the living style. Based on a low cost GSM mobile phone, users are assured that their electric consumers will no longer remain on when the forgotten to switch them off; they shall neither remain off while the owner is away and yet it is time to be switched on. The notification about the on/off status will ensure the energy saving and control for the user. The work brings significant advantages in terms of service capacity and quality. The system shall find switching applications in homes, office, classrooms, etc. In the end, numerous lighting systems, which were mostly manually operated, will be smartly and safely operated. Users will enjoy the system's results: energy efficiency improvement, maintenance cost optimization as well as electrical installation safety from sparks and damages.

\section{REFERENCES}

[1] Michael S. Radio Frequency Systems. In Microwave and RF Design. A system approach, SciTech publishing, Inc., 2010. Ch.3, pp.101-158.

[2] Sultan M. R. G. M., Abdullah A. M. K., Mohammad N. H. and Abu F. M. Design and Implementation of a GSM Based remote home security and appliance control system. Proc. of the 2nd International Conference on Advances in Electrical Engineering, 2013. Pp. 291-295.

[3] Riddhi G., Biswendu C., Debangshu D., Sovan D. and Sivaji C. "Remote Monitoring of Power Frequency Electrical Signals Employing GSM Network. Applications and Innovations in Mobile Computing (AIMMoc), 2014. Pp. 81 - 84.

[4] Kazuaki Y., Wenxi C. and Daming W.. 3G Mobile Phone Applications in Telemedicine - A Survey. Proc. of IEEE Fifth International Conference on Computer and Information Technology, 2005. Pp. 956 - 960.

[5] Marusic L., Skocir P., Petric A. and Jezic G., Homein-Palm - A Mobile Service for Remote Control of Household Energy Consumption. Proc. of IEEE 11th International Conference on Telecommunications, 2011. Pp. 109-115.

[6] Moon, S. W. et al. Implementation of smartphone environment remote control and monitoring system for Android operating system-based robot platform, Proc. of 8th IEEE International Conference on Ubiquitous Robots and Ambient Intelligence, 2011. Pp. 211-214.

[7] Rupam K. S., Ayub M., Himaraka K. and Dhiraj K. Android Interface based GSM Home Security System. Proc. of IEEE International Conference on Issues and Challenges in Intelligent Computing Techniques, 2014. Pp. 196 - 201

[8] Jinkang Z. and Ling Q. Development on Cordless, WLL, Cellular and W-CDMA Systems in China. Proc. of IEEE Asia Pacific Microwave Conference, 1997. Pp. $153-156$
Jesus L. F. and James G. M.. Past and future directions in cellular telephony. Proc. of the Second IEEE International Caracas Conference on Devices, Circuits and Systems, 1998, pp. 7-13

[10] Theodore S. R. et al. Millimeter Wave Mobile Communications for 5G Cellular: It Will Work! IEEE Access, vol.1, 2013. Pp. 335-349

[11] Jeffrey G. A. et al. What Will 5G Be? IEEE Journal on selected areas in communications, vol. 32 , no. 6 , 2014. Pp.1065 - 1082

[12] Cheng-Xiang W. et al. Cellular architecture and key technologies for $5 \mathrm{G}$ wireless communication networks. IEEE Communications Magazine, vol. 52, no 2, 2014, pp. 122 - 130

[13] Stephen C. The big time Build a giant version of the 555 timer IC. IEEE Spectrum., vol.51, no. 3, pp.2526, 2014.

[14] M. Rezal, N.Mariun and I. Aris. Simple Boost Converter using Timer IC 555 for Charging Capacitor Banks. Proc. of IEEE Student Conference on Research and Development, 2010. Pp. 272 - 274

[15] Bimal K. B. Power electronics - a technology review. Proc. of the IEEE Power Electronics Specialists Conference, 1992. Pp. 1303-1334

[16] Texas I. (1988). SN74LS109A Dual J-K PositiveEdge-Triggered Flip-Flops with Clear and Preset [online].

http://www.datasheetarchive.com/74LS109Adatasheet.html

[17] Abhijit C. Current division in Circuit Theory - Circuit analysis and synthesis, Gagan Kapur, Dhanpat Rai \& Co. (P) Ltd., Delhi, 2010, Ch. 1, pp. 52-60.

[18] Fairchild S. (2013), LM555 Single timer [Online]. FTP:

http://www.fairchildsemi.com/ds/LM/LM555.pdf

[19] Unisonic T. (2013). Audio frequency amplifier high frequency OSC NPN transistor [online]. FTP: www.unisonic.com.tw/datasheet/2SC1815.pdf

[20] Tony v. R. (2011). 741 Operational Amplifier [Online].

FTP: http://www.sentex.ca/ mec1995/gadgets/741/741.htm 1

[21] Sergio G., Guido M. and Domenico G. New Macromodels and Measurements for the Analysis of EM1 Effects in 741 Op-amp Circuits. IEEE transactions on electromagnetic compatibility, vol. 33, no. 1, Feb. 1991 , pp. 25-34

[22] On S. (2011). C106 series Sensitive Gate Silicon Controlled Rectifiers. [online]. FTP: www.onsemi.com/pub/Collateral/C106-D.PDF

[23] NXP Semiconductors. (2009). BT151-500R SCR, 12 A, $15 \mathrm{~mA}, \quad 500 \mathrm{~V}, \quad$ SOT78 [online]. FTP: http://www.nxp.com/documents/data_sheet/BT151500R.pdf 


\section{BIOGRAPHIES}

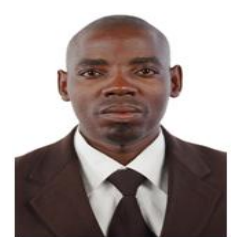

Mr Gerard Rushingabigwi is currently a PhD research student in Electromagnetic fields and Microwave technology. He is Assistant Lecture since January 2011 to date. The research focus is in RF Engineering.

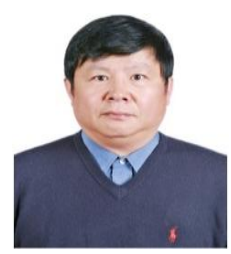

Dr. Liguo Sun is a Professor in the area of Applied Electromagnetism. His work experiences include radio wave propagation, remote sensing applications as well as supervising post graduate research projects.

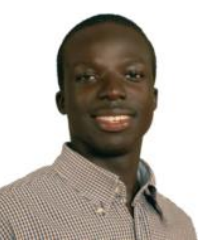

$\mathrm{Mr}$ Godfrey Lugoloobi is working with Edify, a non-profit educational organization based in California. The past experiences include youth mentoring/training as well as RF Engineering team-working for the network optimization in Rwanda.

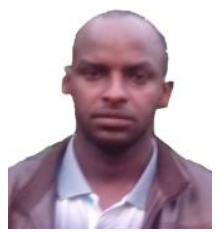

Mr Frank Mwezi is currently employed by Rwanda Civil Aviation Authority. He was trained and is experienced for Doppler Very High Frequency Omni Directional Radio Range (DVOR), radio Maintenance as well as Navigational aids Equipments 